\title{
Over-expression of eukaryotic translation initiation factor 4 gamma 1 correlates with tumor progression and poor prognosis in nasopharyngeal carcinoma
}

\author{
Luxia Tu¹,3, Zhen Liu¹, Xiufang He2, Ying He, Huiling Yang5, Qingping Jiang ${ }^{1}$, Siming Xie', Guanghui Xiao', Xin Li*1, \\ Kaitai Yao*1 and Weiyi Fang*1
}

\begin{abstract}
Background: The aim of the present study was to analyze the expression of eukaryotic translation initiation factor 4 gamma 1 (EIF4G1) in nasopharyngeal carcinoma (NPC) and its correlation with clinicopathologic features, including patients' survival time.

Methods: Using real-time PCR, we detected the expression of EIF4G1 in normal nasopharyngeal tissues, immortalized nasopharyngeal epithelial cell lines NP69, NPC tissues and cell lines. EIF4G1 protein expression in NPC tissues was examined using immunohistochemistry. Survival analysis was performed using Kaplan-Meier method. The effect of EIF4G1 on cell invasion and tumorigenesis were investigated.

Results: The expression levels of EIF4G1 mRNA were significantly greater in NPC tissues and cell lines than those in the normal nasopharyngeal tissues and NP69 cells $(P<0.001)$. Immunohistochemical analysis revealed that the expression of EIF4G1 protein was higher in NPC tissues than that in the nasopharyngeal tissues $(P<0.001)$. In addition, the levels of EIF4G1 protein in tumors were positively correlated with tumor T classification $(P=0.039)$, lymph node involvement ( $N$ classification, $P=0.008)$, and the clinical stages $(P=0.003)$ of NPC patients. Patients with higher EIF4G1 expression had shorter overall survival time $(P=0.019)$. Multivariate analysis showed that EIF4G1 expression was an independent prognostic indicator for the overall survival of NPC patients. Using shRNA to knock down the expression of EIF4G1 not only markedly inhibited cell cycle progression, proliferation, migration, invasion, and colony formation, but also dramatically suppressed in vivo xenograft tumor growth.
\end{abstract}

Conclusion: Our data suggest that EIF4G1 can serve as a biomarker for the prognosis of NPC patients.

\section{Introduction}

Nasopharyngeal carcinoma (NPC) is a common malignant disease in Southern China where its annual incidence rate is more than 20 cases per 100,000 populations. Men are twice as likely to develop NPC as women. The incidence generally increases from ages 20 to 50 [1].

*Correspondence: xinli268@gmail.com, ktyao@fimmu.com

, fangweiyi1975@yahoo.com.cn

Cancer Research Institute, key lab for transcriptomics and proteomics of human fatal diseases supported by ministry of education and Guangdong Province, Southern Medical University, 510515, Guangdong Province, PR China

+ Contributed equally

Full list of author information is available at the end of the article
Because the primary anatomical site of tumor growth is located in a cryptic area and the disease is usually asymptomatic at early stages, the NPC patients tend to present at a more advanced stage with higher metastatic potential. Therefore, it is of great interest to find effective biomarkers for early diagnosis of as well as therapeutic targets for this malignancy.

The tumorigenesis and metastasis of NPC are complex and continuous processes that involve a cascade of oncogene activations [1,2]. Latent membrane protein 1 (LMP1), a protein encoded by Epstein-Barr virus (EBV), is considered as a major oncogenic protein promoting the development of NPC. LMP1-positive cells have greater 
mobility, leading to higher metastatic potential [3] and faster disease progression [4]. Protein $X B P-1$ induces $L M P 1$ expression, and knockdown of $X B P-1$ blocks upregulation of $L M P 1$ in NPC cells. Furthermore, $X B P-1$ significantly correlates with $L M P 1$ expression in NPC tumor biopsies, suggesting that $X B P-1$ can promote virus-associated cancer in a unique way by driving expression of a viral oncogene [5]. Survivin is an inhibitor of apoptosis and promoter of cell proliferation, and it is usually absent in normal adult tissues but present in numerous tumors [6]. In NPC, survivin has been constantly found to be over-expressed [7]. Inhibiting survivin expression can decrease NPC cell viability as well as increase tumor radiosensitivity [8].

In a previous study, we investigated differentially expressed genes between non-cancerous nasopharyngeal tissues and NPC tissues using cDNA microarray. One of the genes showed markedly increased expression in NPC was eukaryotic translation initiation factor (EIF4G1) [7]. EIF4G1 participates in protein translation by serving as a scaffold for several other initiation factors [9]. In addition, recent studies have found that EIF4G1 possesses tumorigenesis activities including promoting angiogenesis [10], inducing malignant transformation [11], and inhibiting apoptosis [12]. In a variety of cancers, including NPC, lung cancer, and breast cancer, the expression levels of EIF4G1 are significantly up-regulated [13-16].

In the present study, we investigated the role of EIF4G1 in the pathogenesis of NPC, and examined its association with clinicopathologic features, including the survival of patients with NPC. We identified the effects of EIF4G1 on cell growth, invasion, and in vivo tumorigenesis, confirmed the increased expression levels of EIF4G1 in primary NPC tissues and cell lines, and found an inverse correlation between the levels of EIF4G1 and clinical outcome of patients with NPC.

\section{Results}

EIF4G1 Was Highly Expressed in NPC Tissues and Cell Lines

We first set out to confirm our previous observation that EIF4G1 was a differentially expressed gene between normal and cancerous nasopharyngeal tissues. Using realtime PCR to measure the expression of EIF4G1 transcripts, we found that EIF4G1 expression was significantly increased in freshly isolated NPC tissues $(\mathrm{n}=10)$ and NPC cell lines $(n=6)$ in comparison to freshly isolated nasopharyngeal tissues $(n=7)$ and the immortalized human nasopharyngeal epithelial cell lines NP69 (Figure 1A) $(\boldsymbol{P}<0.001)$. Among the 6 NPC cell lines, $5-8 \mathrm{~F}$ cells had the highest expression levels of EIF4G1 (Figure $1 \mathrm{~A})$; this cell line is also highly tumorigenic and metastatic $[17,18]$, suggesting of $5-8 \mathrm{~F}$ cells as a good model system for studying the functions of endogenous EIF4G1 by loss-of-function approach.
In addition to the transcript level, using immunohistochemistry, we also found that the levels of EIF4G1 protein were significantly greater in formalin-fixed paraffinembedded (FFPE) NPC tissue samples $(n=137)$ than the non-cancerous nasopharyngeal tissue samples $(\mathrm{n}=53)(P$ $<0.001$ ) (Table 1). We observed the expression of EIF4G1 protein in the cytoplasm of non-cancerous and malignant nasopharyngeal epithelial cells (Figure 1B).

\section{Relationship between Clinicopathological Characteristics and EIF4G1 Expression in Patients with NPC}

The relationship between clinicopathological characteristics and EIF4G1 expression in patients with NPC is summarized in Table 1. We did not find any significant association of EIF4G1 expression with age, sex, smoking status, or distant metastasis (M classification) in 132 patients with NPC. However, we observed that the levels of EIF4G1 expression were closely correlated with the T classification (T1-T2 vs. T3-T4) $(P=0.039)$, lymph node involvement (N classification, N0-N1 vs. N2-N3) $(P=$ $0.008)$, and clinical stage (I-II vs. III-IV) $(P=0.003)$ in NPC patients.

To investigate the prognostic value of EIF4G1 for NPC, we assessed the association between the levels of EIF4G1 expression and patients' survival time in 107 NPC cases with prognosis information available. We observed that the expression levels of EIF4G1 were significantly related to the overall survival of NPC patients. Patients with high levels of EIF4G1 expression had significantly shorter overall survival time than those with low levels of EIF4G1 expression $(P=0.019)$ (Figure $1 C)$. To estimate the clinical significance of various prognostic factors that might influence the survival and tumor progression in NPC patients, univariate analyses were performed. As summarized in Table 2 , the lymph node involvement ( $\mathrm{N}$ classification) $(P=0.032)$, clinical stage $(P=0.023)$, and high expression of EIF4G1 $(P=0.014)$ were statistically significant risk factors affecting the overall survival of NPC patients. To determine the independent prognostic effects of these variables, multivariate analyses were performed using the Cox's proportional hazards model. Results showed that only high expression of EIF4G1 can independently predict the overall survival of NPC patients $(P=0.027)$ (Table 2$)$. Taken together, our findings indicate that the levels of EIF4G1 expression could serve as an effective biomarker for the prognosis of NPC patients.

\section{Reduced EIF4G1 Expression Suppressed the Proliferation, Cell Cycle Progression, Migration, and Invasion of NPC Cells in vitro}

To study the biological function of EIF4G1, we used a lentiviral vector containing shRNA specifically targeting EIF4G1 to stably knock down the endogenous expression 


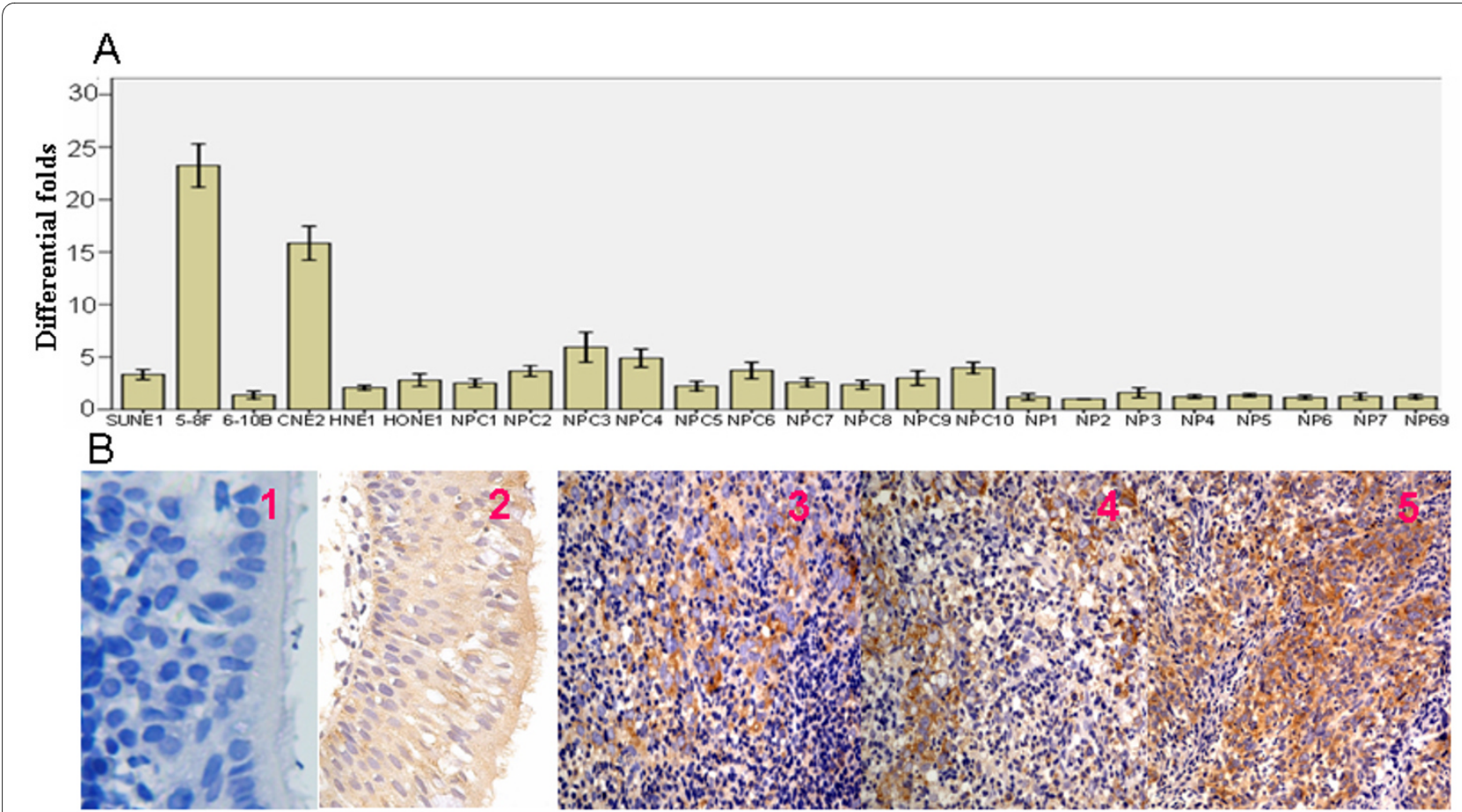

$\mathrm{C}$

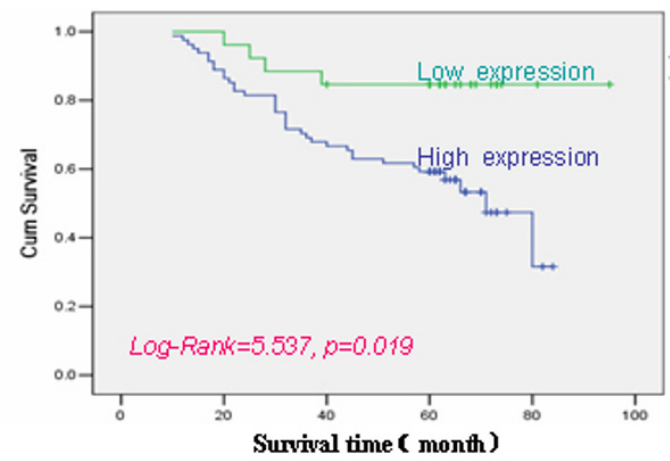

Figure 1 The increased expression levels of EIF4G1 mRNA and protein in NPC tumor tissue and cell lines and their association with the overall survival of NPC patients. A. EIF4G1 mRNA expression in NPC cell lines, tumor tissues, and non-cancerous nasopharyngeal (NP) tissues. EIF4G1 mRNA level was relatively high in NPC tissue, NPC cell lines (except 6-10B cells) comparing to nasopharyngeal tissue and NP69 cells. B. EIF4G1 protein expression in NPC and nasopharyngeal tissues.(1) Negative control; (2) Weak expression of EIF4G1 in nasopharyngeal tissues; (3-5) Strong expression of EIF4G1 in NPC tissues (magnification 400X). C. Kaplan--Meier survival analysis of the overall survival time in 107 NPC patients based on the levels of EIF4G1 protein expression. The log-rank test was used.

of EIF4G1 in 5-8F cells, an NPC cell line with high levels of endogenous EIF4G1. As shown in Figure 2A, comparing to the control (shRNA-Ctrl), cells transfected with shRNA-EIF4G1 had significantly decreased levels of EIF4G1 protein.

Subsequently, we examined the effect of decreased EIF4G1 expression on NPC cell growth in vivo. Using MTT assay, we found that the parental NPC 5-8F cells had a similar growth rate as shRNA-Ctrl cells over a seven-day period, while starting from day 2 the growth of shRNA-EIF4G1 cells was significantly slower than the former two cells $(P<0.05)$ (Figure 2B). Interestingly, the consistent result also appeared in the plate clone formation test. Both the parental 5-8F cells and the shRNA-Ctrl cells formed a similar number of colonies on plate over a two-week period [(73 \pm 3.6$)$ vs. $(74.3 \pm 4.93)]$. In contrast, knocking down endogenous EIF4G1 could dramatically reduce the number of colonies $(40 \pm 5.0)(\mathrm{P}<0.05)$ (Figure 2C).

We also measured the alteration of cell cycle progression by EIF4G1 knock-down. Using flow cytometry analysis, we found that EIF4G1-deficient cells showed a 
Table 1: Protein expression of EIF4G1 in NPC and NP and Correlation of clinicopathological features of the patients with NPC and expression of EIF4G 1 protein

EIF4G1 protein expression

\begin{tabular}{|c|c|c|c|c|c|c|}
\hline \multirow[b]{2}{*}{ Characteristics } & \multicolumn{6}{|c|}{ EIF4G1 protein expression } \\
\hline & $\mathbf{N}$ & Negative(n) & $\operatorname{Low}(n)$ & Medium(n) & High(n) & $P$ value \\
\hline \multicolumn{7}{|l|}{ Group } \\
\hline NPC & 132 & 2 & 27 & 41 & 62 & \\
\hline NP & 53 & 4 & 26 & 19 & 4 & $p=0.000$ \\
\hline \multicolumn{7}{|l|}{ Sex } \\
\hline Male & 94 & 2 & 19 & 31 & 42 & \\
\hline Female & 38 & 0 & 8 & 10 & 20 & $p=0.477$ \\
\hline \multicolumn{7}{|l|}{ Age } \\
\hline$\geq 45$ years & 81 & 2 & 15 & 24 & 40 & \\
\hline$<45$ years & 51 & 0 & 12 & 17 & 22 & $p=0.557$ \\
\hline \multicolumn{7}{|l|}{ Smoking } \\
\hline No & 100 & 0 & 21 & 29 & 50 & \\
\hline Yes & 32 & 2 & 6 & 12 & 12 & $p=0.226$ \\
\hline \multicolumn{7}{|l|}{ T classfication } \\
\hline $\mathrm{T} 1+\mathrm{T} 2$ & 91 & 2 & 22 & 29 & 38 & \\
\hline $\mathrm{T} 3+\mathrm{T} 4$ & 41 & 0 & 5 & 12 & 24 & $p=0.039^{*}$ \\
\hline \multicolumn{7}{|l|}{ N classfication } \\
\hline $\mathrm{N} 0+\mathrm{N} 1$ & 57 & 2 & 14 & 22 & 19 & \\
\hline $\mathrm{N} 2+\mathrm{N} 3$ & 75 & 0 & 13 & 19 & 43 & $p=0.008^{*}$ \\
\hline \multicolumn{7}{|l|}{ M classfication } \\
\hline Mo & 127 & 2 & 26 & 40 & 59 & \\
\hline M1 & 5 & 0 & 1 & 1 & 3 & $p=0.625$ \\
\hline \multicolumn{7}{|l|}{ Clinical stage } \\
\hline$I+I I$ & & 2 & 11 & 16 & 11 & \\
\hline III+IV & 41 & 0 & 16 & 25 & 51 & $p=0.003^{*}$ \\
\hline
\end{tabular}

significant increase in $\mathrm{S}$ phase proportion and a decrease in $\mathrm{G} 2 / \mathrm{M}$ proportion compared to the shRNA-Ctrl and the parental $5-8$ F cells $(P<0.05)$ (Figure $3 \mathrm{~A})$.

Cell migration and invasion are integral steps for the process of tumor development and metastasis. When testing the abilities of $5-8 \mathrm{~F}$ cells to migrate/invade through the 8 - $\mu \mathrm{m}$ pores on the polycarbonate membrane with or without pre-coated matrigel, we found that the knock-down of endogenous EIF4G1 expression could significantly reduce cell migration and invasion as compared to the parental or shRNA-Ctrl cells $(P<0.05)$ (Figures 3B, C).

\section{Knock-down of EIF4G1 Inhibited in vivo Xenograft Tumor Growth}

In addition to examining the biological functions of EIF4G1 in vitro, we also assessed the in vivo function of
EIF4G1 in a xenograft tumor transplantation model. After subcutaneously transplanting the cells containing shRNA-Ctrl or shRNA-EIF4G1 lentiviral vectors into nude mice, we monitored the tumor growth over a 25-day period. As shown in Figure 4A, by measuring the tumor weights, we found that shRNA-EIF4G1 cells gave rise to significantly smaller tumors than shRNA-Ctrl cells did ( $P$ $<0.05)$. Immunohistochemistry assay revealed that protein expression of EIF4G1 was significantly decreased in the tumors induced by shRNA-EIF4G1 cells compared to those induced by shRNA-Ctrl cells (Figure 4B), which was in consistent with the in vitro results in cells transfected with shRNA-EIF4G1 or the control vectors (Figure 2A).

\section{EIF4G1 Inhibited the Expression of PDCD4 in NPC cells}

The above results indicated that over-expression EIF4G1 may play an important role in promoting the develop- 
Table 2: Summary of univariate and multivariate Cox regression analysis of overall survival duration

\begin{tabular}{|c|c|c|c|c|c|c|}
\hline \multirow[b]{2}{*}{ Parameter } & \multicolumn{3}{|c|}{ Univariate analysis } & \multicolumn{3}{|c|}{ Multivariate analysis } \\
\hline & $\mathbf{P}$ & HR & $95 \% \mathrm{Cl}$ & $\mathbf{P}$ & HR & $95 \% \mathrm{Cl}$ \\
\hline \multicolumn{7}{|l|}{ Age } \\
\hline$>45$ vs. $\leq 45$ years & 0.497 & 1.252 & $0.655-2.391$ & & & \\
\hline \multicolumn{7}{|l|}{ Gender } \\
\hline Male vs. female & 0.966 & 1.015 & $0.516-1.997$ & & & \\
\hline \multicolumn{7}{|l|}{ Smoking } \\
\hline No vs. Yes & 0.239 & 0.628 & $0.290-1.362$ & & & \\
\hline \multicolumn{7}{|l|}{ T classification } \\
\hline$T_{1}-T_{2}$ vs. $T_{3}-T_{4}$ & 0.122 & 1.631 & $0.877-3.031$ & & & \\
\hline \multicolumn{7}{|l|}{ N classification } \\
\hline $\mathrm{N}_{0}-\mathrm{N} 1$ vs. $\mathrm{N}_{2--} \mathrm{N}_{3}$ & 0.032 & 2.034 & $1.062-3.898$ & 0.455 & 1.393 & $0.584-3.323$ \\
\hline \multicolumn{7}{|l|}{ M classification } \\
\hline$M_{0}$ vs. $M_{1}$ & 0.492 & 1.662 & $0.390-7.073$ & & & \\
\hline \multicolumn{7}{|l|}{ Clinical stage } \\
\hline I-II vs. III-IV & 0.023 & 2.465 & $1.132-5.368$ & 0.360 & 1.629 & $0.572-4.638$ \\
\hline \multicolumn{7}{|l|}{ EIF4G1 expression } \\
\hline $\begin{array}{l}\text { High expression vs. Low } \\
\text { expression* }\end{array}$ & 0.014 & 3.678 & $1.308-10.344$ & 0.027 & 3.251 & $1.147-9.214$ \\
\hline
\end{tabular}

*High expression: medium and high expression; Low expression: negative and low expression;

ment of NPC. We further examined the effect of EIF4G1 on the expression of $P D C D 4$, a key tumor suppressor protein interacting with EIF4G1 and controlling tumor growth and invasion [19]. We speculated that reducing the levels of EIF4G1 activates the effects of PDCD4. To test this hypothesis, we measured the protein levels of PDCD4 in cells deficient of EIF4G1. Comparing to the parental $5-8 \mathrm{~F}$ cells and cells containing the control vector, EIF4G1-deficient cells had increased levels of PDCD4 protein (Figure 5A). Our results suggest that EIF4G1 may be involved in the development of NPC by antagonizing the effect of PDCD4.

\section{Discussion}

It is well known that the majority of NPC deaths result from tumor metastases rather than from primary tumors. However, the molecular mechanisms underlying the regulation of tumor cell invasion and metastasis of NPC remain incompletely understood. EIF4G1, a member of the translational initiation factor family, is recognized as the central organizing protein in the recruitment of mRNA during translational initiation. Gradually accumulated evidences indicate that increased EIF4G1 expression may play an oncogenic role and promote the process of tumorigenesis. For instance, over-expression of
EIF4G1 has been found in inflammatory breast cancer (IBC) and promotes the formation of IBC tumor emboli by enhancing translation of IRES-containing $p 120$ mRNA, which facilitated tumor cell survival [15]. In addition, frequent amplification of EIF4G1 on chromosome 3q27.1 and over-expression of EI4G1 mRNA was also displayed in lung cancer and hypopharyngeal cancer [13,14], which suggest the involvement of EIF4G1 in tumorigenesis $[11,20]$. Yet, it remains largely unknown about the role of EIF4G1 in the pathogenesis of NPC.

In the previous microarray study, we found that the levels of EIF4G1 mRNA in NPC were increased compared to noncancerous nasopharyngeal tissues [7]. In this report, we further presented the proof that EIF4G1 was overexpressed at both mRNA and protein levels in NPC tissues and cell lines. Furthermore, we found that EIF4G1 over-expression was significantly associated with $\mathrm{T}$ classification, lymph node involvement, and clinical stages of NPC patients. Our results also indicated that EIF4G1 protein expression was inversely correlated with patients' overall survival time. NPC patients with higher expression levels of EIF4G1 protein had shorter survival time, and the protein levels of EIF4G1 were an independent prognostic factor. These results suggested the clinical significance of EIF4G1 as a biomarker for NPC prognosis. 


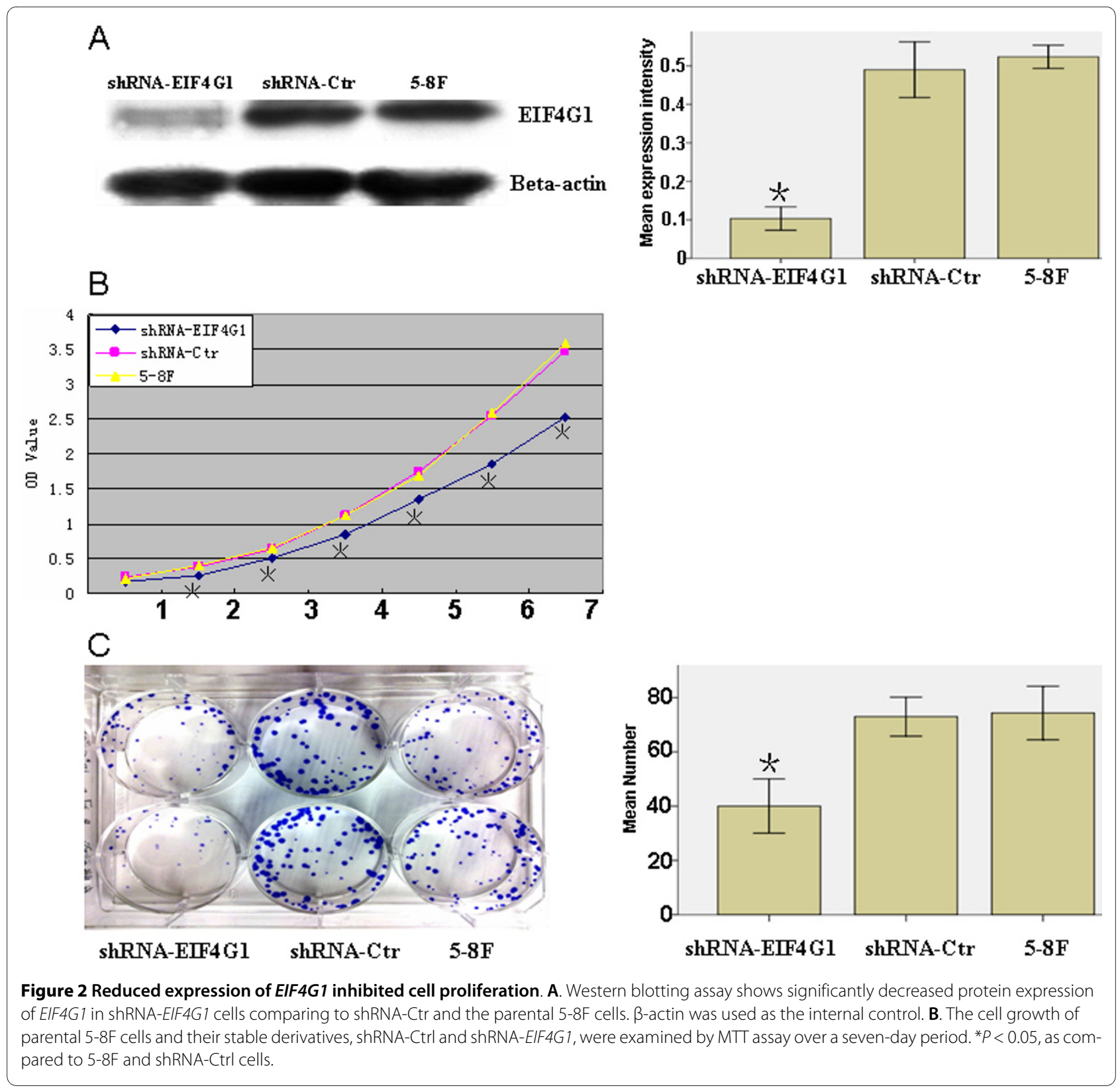

To understand the biological functions of EIF4G1, we employed the loss-of-function approach, that is, by knocking down the expression level of endogenous EIF4G1. To achieve this purpose, we chose to use NPC 5$8 \mathrm{~F}$ cells, a cell line with high tumorigenic and metastatic ability. The 5-8F cells exhibit the highest expression levels of endogenous EIF4G1 in all the six NPC cell lines examined, and thus represent an ideal model for our study. Using this system, we identified the roles of EIF4G1 in promoting cell proliferation, cell cycle, migration, and invasion; we further found that EIF4G1 could enhance tumorigenesis in vivo. These results strongly suggest an oncogenic role of EIF4G1 in NPC development.
EIF4G1 may be used as a useful molecular marker for NPC and an indicator for tumor progression and prognosis. In combination with other biomarkers of NPC, EIF4G1 would be useful for novel therapeutic strategies. Assembly of the EIF4E/EIF4G complex plays a central role in the regulation of gene expression at the level of translation initiation. This complex is regulated by the $4 E B P 1$, a translational repressor that inhibits the function of eukaryotic translation initiation factor $4 \mathrm{E}$ (EIF4E), which compete with EIF4G1 for binding to eIF4E and have tumor-suppressor activity[21]. To pharmacologically mimic 4E-BP function Moerke et al developed the most potent small-molecule compound 4EGI-1 for disrupting EIF4E/EIF4G association, which inhibited cap- 


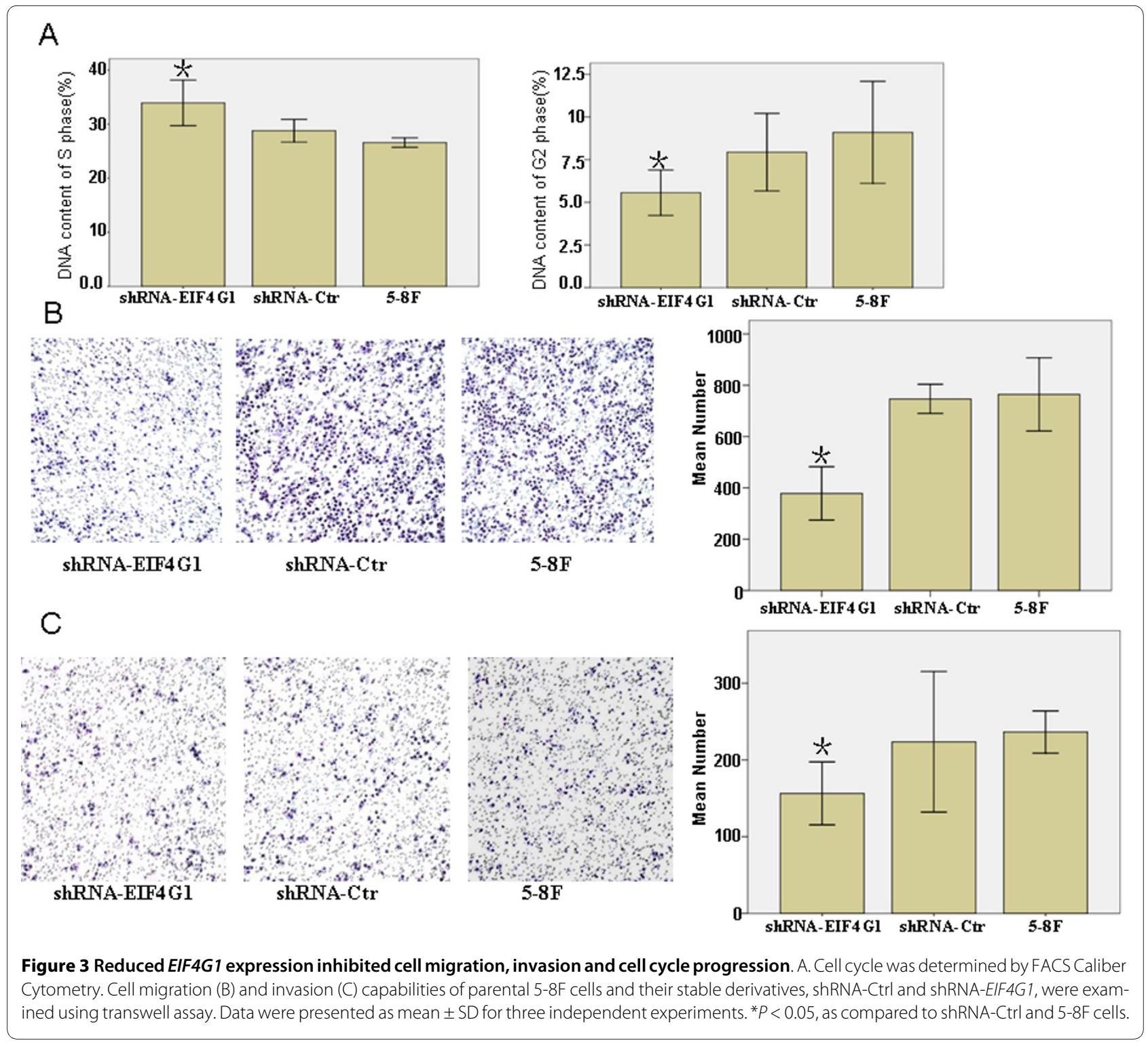

dependent translation but not initiation factor independent translation. While 4EGI-1 displaces EIF4G from $E I F 4 E$, it effectively enhances $4 E B P 1$, a translational repressor that inhibits the function of eukaryotic translation initiation factor $4 \mathrm{E}(E I F-4 E)$, association with $E I F 4 E$ both in vitro and in cells, and suppressed cell proliferation [22,23]. Additionally, EIF4G1 has been reported to implicate in another signal pathway. For example, EIF4A/ EIF4G complex has been shown to be involved in the key regulation of translation initiation. Tumor suppressor PDCD4 [24,25] could compete with EIF4A for binding to EIF4G1 and thus inhibit the initialization of translation [26]. Although PDCD4 is known to be a key regulator that controls tumor growth and invasion [27], the role of PDCD4 in NPC progression remains unclear. Recently, in a microarray study, we observed a significant downexpression of PDCD4 in NPC samples [7]. We therefore speculated that EIF4G1 may play a role in NPC by inhibiting the functions of PDCD4. In the present study, we found that the reduction of endogenous EIF4G1 protein expression increased the expression levels of PDCD4. This result supports the potential involvement of EIF4G1 in regulating $P D C D 4$ expression.

In summary, our results provided the first evidence that EIF4G1 may be involved in the development of NPC. In addition, we also demonstrated that EIF4G1 could serve as a biomarker for the prognosis of NPC. Further works are needed to investigate the mechanisms and pathways of NPC pathogenesis mediated by EIF4G1.

\section{Materials and methods Cell Culture and Sample Collection}

NPC cell lines 5-8F, 6-10B, CNE2, HONE1, HNE1, and SUNE1 were maintained in RPMI 1640 culture medium 


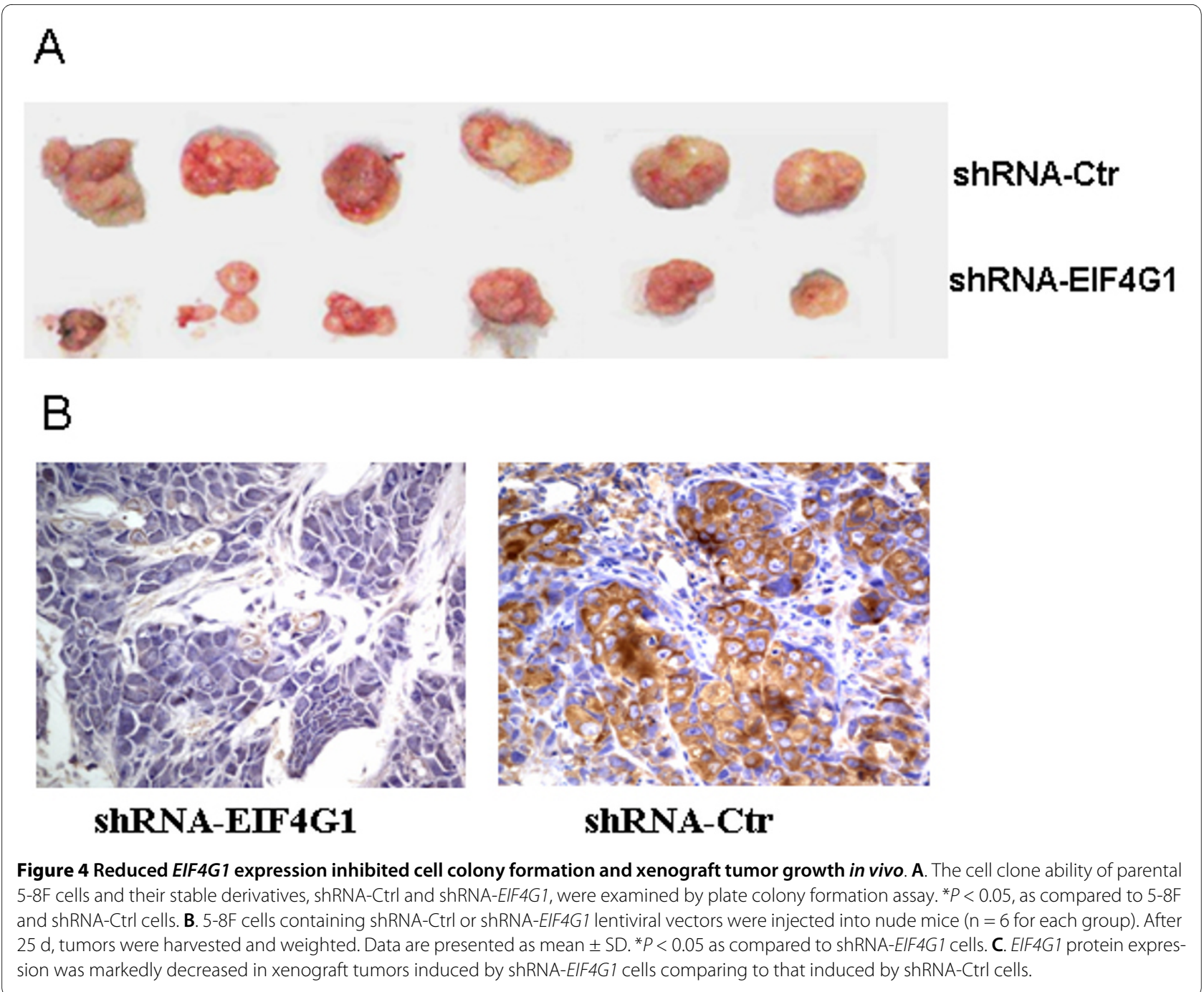

supplemented with $10 \%$ newborn calf serum (NBCS) (PAA Laboratories, Austria). NP69, an immortalized human nasopharyngeal epithelial cell line, was grown in defined-KSFM medium supplemented with EGF (Invitrogen, Carlsbad, CA). All of the cell lines were incubated in a humidified chamber with $5 \% \mathrm{CO}_{2}$ at $37^{\circ} \mathrm{C}$. Seven primary NPC tissues, 5 noncancerous nasopharyngeal tissues, 132 paraffin-embedded NPC specimens (107 cases with prognosis information), and 53 noncancerous paraffin-embedded nasopharyngeal specimens were obtained from People's Hospital of Zhongshan City, China, at the time of diagnosis before any therapy. An informed consent was obtained from each patient. All freshly collected samples were immediately stored in liquid nitrogen.

\section{Real-time PCR}

Real-time PCR was performed to measure the expression of EIF4G1 mRNA in NPC cell lines, tumor tissues, or normal nasopharyngeal tissues using SYBR Premix Ex Taq (Takara, Japan) as described previously [28]. The primers used were: forward 5'-TTGTGGATGATGGTGGCT-3' and reverse 5'-TTATCTGTGCTTTCTGTGGGT-3'. GAPDH was used as an internal control and the primers were: forward 5'-GCACCGTCAAGGCTGAGAAC-3' and reverse 5'-TGGTGAAGACGCCAGTGGA-3'. Each measurement was repeated three times.

\section{Immunohistochemistry}

Paraffin sections $(3 \mu \mathrm{m})$ from 132 NPC and 53 nasopharyngeal samples were deparaffinized in $100 \%$ xylene and re-hydrated in descending ethanol series according to standard protocols [7]. Heat-induced antigen retrieval was performed in $10 \mathrm{mM}$ citrate buffer for $2 \mathrm{~min}$ at $100^{\circ} \mathrm{C}$. The endogenous peroxidase activity and non-specific antigens were blocked with peroxidase blocking reagent containing $3 \%$ hydrogen peroxide and serum. The slides were incubated with rabbit anti-human EIF4G1 antibody (1:50) (Cell Signaling Technology, CA, USA) for $1 \mathrm{~h}$ at $37^{\circ} \mathrm{C}$. After washing, the sections were incubated with biotin-labeled goat anti-rabbit IgG antibody for 10 


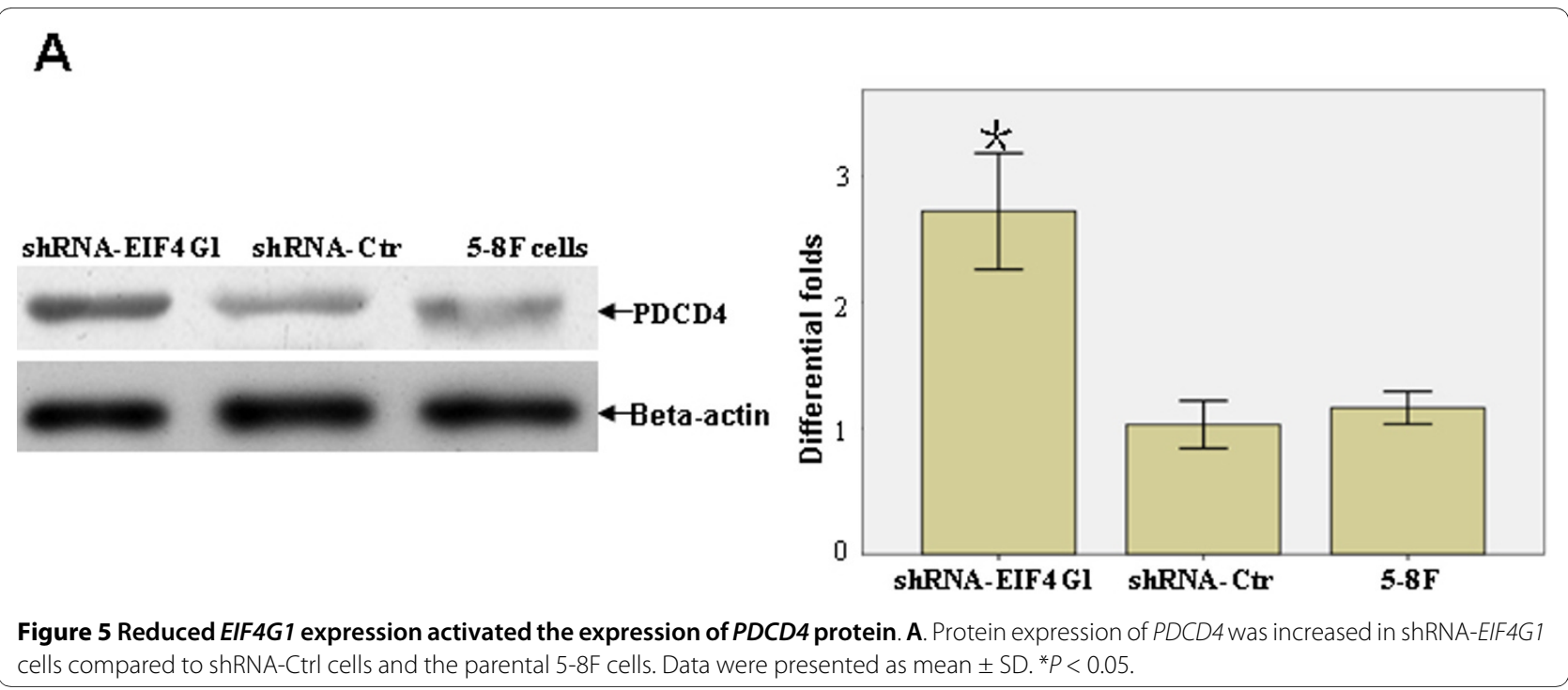

min at room temperature followed by incubation with streptavidin-conjugated horseradish peroxidase (HRP) (Maixin Inc, China). The peroxidase reaction was developed with 3,3-diaminobenzidine chromogen solution in DAB buffer substrate. The slides were reviewed and scored independently by two pathologists blinded to the clinical parameters. The staining intensity was scored as described $[29,30]$. The extent of the staining, defined as the percentage of positive staining cells in relation to the whole field, was scored on a scale of 0 to 3 as $0:<10 \%$; 1 : $10-25 \%$; $2: 26-75 \%$; and $3: \geq 76 \%$. The sum of the stainingintensity and staining-extent scores (0-6) was used as the final staining score for EIF4G1. For statistical analysis, a final staining score of $0,1 \sim 2,3 \sim 4$, and 5 6 were respectively considered to be negative, low, medium, and high expression levels.

\section{Establishment of NPC 5-8F cell line with stably expressing shRNA-EIF4G1}

The construction of lentiviral vector of shRNA targeting EIF4G1 and establishment of NPC 5-8F cell line stably expressing shRNA had been described previously $[17,18,31]$. In brief, we selected one sequence for targeting the EIF4G1 gene using the BLOCK-It RNAi Designer (Invitrogen, Carlsbad, CA). The preparation of lentiviral vectors expressing human EIF4G1 short hairpin RNA (shRNA) was performed using the BLOCK-It Lentiviral RNAi Expression System (Invitrogen, Carlsbad, CA), following the manufacturer's instruction and replicationincompetent lentivirus was produced by cotransfection of the pLenti6/EIF4G1 expression vector and ViraPower packaging mix (Invitrogen) containing an optimized mixture of three packaging plasmids: pLP1, pLP2, and pLP/ VSVG into 293FT cells. NPC 5-8F cells were infected with lentiviral particles containing specific or negative control vectors and selected for stable integrants by cul- turing a complete medium containing blasticidin. After 15 days of selection, there were no viable cells in mock wells and discrete blasticidin resistance colonies. The total RNA of these cell clones was isolated, and the levels of EIF4G1 mRNA were measured using real-time PCR as described above.

\section{Western blot Analysis}

Cells were lysed in RIPA Buffer (50 mM Tris- $\mathrm{HCl} \mathrm{pH} \mathrm{8.0,}$ $1 \mathrm{mM}$ EDTA pH 8.0, $5 \mathrm{mM}$ DTT, 2\% SDS), and protein concentration was determined using BCA assay (Beyotime Inc, China). Total protein $(30 \mu \mathrm{g})$ was resolved using a $10 \%$ SDS-PAGE gel and transferred onto a polyvinylidene fluoride (PVDF) membrane. The primary antibodies used were rabbit polyclonal anti-EIF4G1 antibody(1:500), anti- $A C T B$ antibody(1:400) (both from Santa Cruz Biotechnology, CA, USA) and PDCD4(1:500, Abcam Inc., Cambridge, MA). An HRP-conjugated antirabbit IgG antibody was used as the secondary antibody (Zhongshan Inc, China).

\section{Cell Proliferation and Cell Cycle Analyses}

Cell proliferation was analyzed using MTT assay (Sigma, St. Louis, USA). Briefly, $1 \times 10^{3}$ cells were seeded into a 96-well plate with quadruplicate repeat for each condition. After $72 \mathrm{~h}$ of incubation, MTT reagent was added to each well and incubated for $4 \mathrm{~h}$. The formazan crystals formed by viable cells were then solubilized in DMSO and measured at $490 \mathrm{~nm}$ for the absorbance $(\mathrm{A})$ values. Each experiment was performed in triplicates.

To evaluate cell cycle distribution, cells were seeded on $10 \mathrm{~cm}$-diameter plates in RPMI 1640 culture medium containing $10 \%$ NBCS. After $48 \mathrm{~h}$ of incubation, a total of $1 \times 10^{6}$ cells were harvested, rinsed with cold PBS, and fixed with $70 \%$ ice-cold ethanol for $48 \mathrm{~h}$ at $4^{\circ} \mathrm{C}$. Fixed cells were rinsed with cold PBS followed by incubation with 
PBS containing $10 \mu \mathrm{g} / \mathrm{mL}$ propidium iodide and $0.5 \mathrm{mg} /$ $\mathrm{mL}$ RNase A for $15 \mathrm{~min}$ at $37^{\circ} \mathrm{C}$. The DNA content of labeled cells was acquired using FACS Caliber cytometry (BD Biosciences). Each experiment was performed in triplicates.

\section{In vitro Cell Migration and Invasion Assays}

Cells growing in the log phase were treated with trypsin and re-suspended as single-cell solution. A total of $1 \times$ $10^{5}$ cells were seeded on a fibronectin-coated polycarbonate membrane insert in a transwell apparatus (Corning Inc., Corning, NY). In the lower chamber, $600 \mu \mathrm{l}$ of RPMI 1640 with $10 \%$ NBCS was added as chemoattractant. After the cells were incubated for $12 \mathrm{~h}$, the insert was washed with PBS, and cells on the top surface of the insert were removed by a cotton swab. Cells adhering to the lower surface were fixed with methanol, stained with Giemsa, and counted under a microscope in five predetermined fields $(\times 200)$. For the Matrigel invasion assay, the procedure was similar with the cell migration assay, except that the transwell membrane was precoated with ECMatrix $^{\text {ma }}$ and the cells were incubated for $14 \mathrm{~h}$. All assays were independently repeated at least three times.

\section{Colony Formation Assay}

About 100 cells were added to each well of a 6-well culture plate, and each cell group contained 2 wells. After 2 weeks of incubation, cells were washed twice with PBS and stained with Giemsa solution. The number of colonies containing $\geq 50$ cells was counted under a microscope. The colony formation efficiency was calculated as: efficiency $=$ (number of colonies/number of cells inoculated) $\times 100 \%$. Each experiment was performed in triplicates.

\section{Growth of Tumor Xenografts in Nude Mice}

All animal studies were conducted in accordance with the principles and procedures outlined in the National Institutes of Health (NIH) Guide for the Care and Use of Animals under assurance number A3873-1. Nude mice of 4 to 6 weeks old $(\mathrm{n}=6)$ were purchased from the Animal Center, Southern Medical University. A total of $1 \times 10^{6}$ cells growing in log phase were re-suspended in serumfree RPMI 1640 medium and injected subcutaneously into the nude mice. To minimize inter-individual variation, cells containing control vector and cells containing shRNA-EIF4G1 vector were injected symmetrically to the either flank of the same mice. After $25 \mathrm{~d}$, mice were sacrificed and tumors isolated and weighted. EIF4G1 protein levels in the xenograft tumors were examined using immunohistochemistry assay.

\section{Statistical analysis}

All data were analyzed for statistical significance using SPSS 13.0 software. The Mann-Whitney U test was applied to the analysis of relationship between EIF4G1 expression levels and clinicopathologic characteristics. Survival analysis was performed using Kaplan-Meier method (the log-rank test). Multivariate Cox proportional hazards method was used for analyzing the relationship between the variables and patient's survival time. One-way ANOVA was used to determine the differences between groups for all in vitro and in vivo analyses. A $P$ value of less than 0.05 was considered statistically significant.

\section{Disclosure of Potential Conflict of interests}

The authors declare that they have no competing interests.

\section{Authors' contributions}

LT, ZL, and WF carried out the molecular and cell biology studies. WF and ZL participated in the design of the study and performed the statistical analysis, collected, analyzed, and interpreted data and wrote the manuscript. XL interpreted data. GX revised the manuscript. XH, QJ, YH and SX collected and analyzed data. WF, KY supervised all the work. All authors have read and approved the final manuscript.

\section{Acknowledgements}

Grants support: The National Nature Science Fund of China (No. 30872856), United Funds of the National Natural Science Foundation of China and the Government of Guangdong Province (U0732006), The National 863 High Technology Research and Development Program of China (No. 2006AA02A404)

\section{Author Details}

${ }^{1}$ Cancer Research Institute, key lab for transcriptomics and proteomics of human fatal diseases supported by ministry of education and Guangdong Province, Southern Medical University, 510515, Guangdong Province, PR China , 2Department of Otorhinolaryngology, People's hospital of Zhongshan City, 528403, Guangdong Province, PR China, ${ }^{3}$ Department of Otorhinolaryngology, Nanfang hospital of Southern Medical University, 510515, Guangdong Province, PR China, ${ }^{4}$ Department of Pathology of the first affiliated hospital, Nanchang University, Jiangxi Province, PR China, 330006 and Institute of Clinical Medicine, First Affiliated Hospital of University of South China, Hengyang City, 421001, Hunan Province, PR China

Received: 9 September 2009 Accepted: 16 April 2010

Published: 16 April 2010

\section{References}

1. Cho WC: Nasopharyngeal carcinoma: molecular biomarker discovery and progress. Mol Cancer 2007, 6:1.

2. Chou J, Lin YC, Kim J, You L, Xu Z, He B, Jablons DM: Nasopharyngeal carcinoma--review of the molecular mechanisms of tumorigenesis. Head Neck 2008, 30:946-963.

3. Ozyar E, Ayhan A, Korcum AF, Atahan IL: Prognostic role of Epstein-Barr virus latent membrane protein-1 and interleukin-10 expression in patients with nasopharyngeal carcinoma. Cancer Invest 2004, 22:483-491.

4. Liu LT, Peng JP, Chang HC, Hung WC: RECK is a target of Epstein-Barr virus latent membrane protein 1. Oncogene 2003, 22:8263-8270.

5. Hsiao JR, Chang KC, Chen CW, Wu SY, Su IJ, Hsu MC, Jin YT, Tsai ST, Takada $\mathrm{K}$, Chang Y: Endoplasmic reticulum stress triggers XBP-1-mediated upregulation of an $\mathrm{EBV}$ oncoprotein in nasopharyngeal carcinoma. Cancer Res 2009, 69:4461-4467.

6. Ambrosini G, Adida C, Altieri DC: A novel anti-apoptosis gene, survivin, expressed in cancer and lymphoma. Nat Med 1997, 3:917-921.

7. Fang W, Li X, Jiang Q, Liu Z, Yang H, Wang S, Xie S, Liu Q, Liu T, Huang J, et al.: Transcriptional patterns, biomarkers and pathways characterizing nasopharyngeal carcinoma of Southern China. J Trans/ Med 2008, 6:32

8. Jiang W, Liao Y, Zhao S, Wu B, Zhou R, Wei R, Zhang J, He Y, Wu H: Role of enhanced radiosensitivity and the tumor-specific suicide gene vector 
in gene therapy of nasopharyngeal carcinoma. $J$ Radiat Res (Tokyo) 2007, 48:211-218.

9. Prevot D, Decimo D, Herbreteau CH, Roux F, Garin J, Darlix JL, OhImann T: Characterization of a novel RNA-binding region of elF4GI critical for ribosomal scanning. EMBO J 2003, 22:1909-1921.

10. Braunstein S, Karpisheva K, Pola C, Goldberg J, Hochman T, Yee H, Cangiarella J, Arju R, Formenti SC, Schneider RJ: A hypoxia-controlled cap-dependent to cap-independent translation switch in breast cancer. Mol Cell 2007, 28:501-512.

11. Fukuchi-Shimogori T, Ishii I, Kashiwagi K, Mashiba H, Ekimoto H, Igarashi K: Malignant transformation by overproduction of translation initiation factor elF4G. Cancer Res 1997, 57:5041-5044.

12. Prevot $D$, Darlix JL, Ohlmann T: Conducting the initiation of protein synthesis: the role of elF4G. Biol Cell 2003, 95:141-156.

13. Cromer A, Carles A, Millon R, Ganguli G, Chalmel F, Lemaire F, Young J, Dembele D, Thibault C, Muller D, et al:: Identification of genes associated with tumorigenesis and metastatic potential of hypopharyngeal cancer by microarray analysis. Oncogene 2004, 23:2484-2498.

14. Comtesse N, Keller A, Diesinger I, Bauer C, Kayser K, Huwer H, Lenhof HP, Meese E: Frequent overexpression of the genes FXR1, CLAPM1 and EIF4G located on amplicon 3q26-27 in squamous cell carcinoma of the lung. Int J Cancer 2007, 120:2538-2544.

15. Silvera D, Arju R, Darvishian F, Levine PH, Zolfaghari L, Goldberg J, Hochman T, Formenti SC, Schneider RJ: Essential role for elF4GI overexpression in the pathogenesis of inflammatory breast cancer. Nat Cell Biol 2009, 11:903-908.

16. Bauer C, Brass N, Diesinger I, Kayser K, Grasser FA, Meese E: Overexpression of the eukaryotic translation initiation factor $4 \mathrm{G}$ (elF4G-1) in squamous cell lung carcinoma. Int J Cancer 2002, 98:181-185.

17. Song LB, Yan J, Jian SW, Zhang L, Li MZ, Li D, Wang HM: [Molecular mechanisms of tumorgenesis and metastasis in nasopharyngeal carcinoma cell sublines]. Ai Zheng 2002, 21:158-162.

18. Liu T, Ding Y, Xie W, Li Z, Bai X, Li X, Fang W, Ren C, Wang S, Hoffman RM, Yao K: An imageable metastatic treatment model of nasopharyngeal carcinoma. Clin Cancer Res 2007, 13:3960-3967.

19. Zakowicz H, Yang HS, Stark C, Wlodawer A, Laronde-Leblanc N, Colburn $\mathrm{NH}$ : Mutational analysis of the DEAD-box RNA helicase elF4All characterizes its interaction with transformation suppressor Pdcd4 and elF4GI. RNA 2005, 11:261-274.

20. Yoshida M, Tomitori H, Machi Y, Hagihara M, Higashi K, Goda H, Ohya T, Niitsu M, Kashiwagi K, Igarashi K: Acrolein toxicity: Comparison with reactive oxygen species. Biochem Biophys Res Commun 2009, 378:313-318

21. Averous J, Proud CG: When translation meets transformation: the mTOR story. Oncogene 2006, 25:6423-6435.

22. Moerke NJ, Aktas H, Chen H, Cantel S, Reibarkh MY, Fahmy A, Gross JD, Degterev A, Yuan J, Chorev M, et al.: Small-molecule inhibition of the interaction between the translation initiation factors elF4E and elF4G. Cell 2007, 128:257-267.

23. Chung J, Bachelder RE, Lipscomb EA, Shaw LM, Mercurio AM: Integrin (alpha 6 beta 4) regulation of elF-4E activity and VEGF translation: a survival mechanism for carcinoma cells. J Cell Biol 2002, 158:165-174.

24. Wei N, Liu SS, Leung TH, Tam KF, Liao XY, Cheung AN, Chan KK, Ngan HY: Loss of Programmed cell death $4(\mathrm{Pdcd} 4)$ associates with the progression of ovarian cancer. Mol Cancer 2009, 8:70.

25. Sun Z, Yang P, Aubry MC, Kosari F, Endo C, Molina J, Vasmatzis G: Can gene expression profiling predict survival for patients with squamous cell carcinoma of the lung? Mol Cancer 2004, 3:35.

26. Yang HS, Jansen AP, Komar AA, Zheng X, Merrick WC, Costes S, Lockett SJ, Sonenberg N, Colburn NH: The transformation suppressor Pdcd4 is a novel eukaryotic translation initiation factor $4 \mathrm{~A}$ binding protein that inhibits translation. Mol Cell Biol 2003, 23:26-37.

27. Zhang S, Li J, Jiang Y, Xu Y, Qin C: Programmed cell death 4 (PDCD4) suppresses metastastic potential of human hepatocellular carcinoma cells. J Exp Clin Cancer Res 2009, 28:71.

28. Xie SM, Fang WY, Liu Z, Wang SX, Li X, Liu TF, Xie WB, Yao KT: Lentivirusmediated RNAi silencing targeting $A B C C 2$ increasing the sensitivity of a human nasopharyngeal carcinoma cell line against cisplatin. J Trans/ Med 2008, 6:55.

29. Wang S, Zhou J, Wang XY, Hao JM, Chen JZ, Zhang XM, Jin H, Liu L, Zhang YF, Liu J, et al:: Down-regulated expression of SATB2 is associated with metastasis and poor prognosis in colorectal cancer. J Pathol 2009, 219:114-122.

30. Masunaga R, Kohno H, Dhar DK, Ohno S, Shibakita M, Kinugasa S, Yoshimura H, Tachibana M, Kubota H, Nagasue N: Cyclooxygenase-2 expression correlates with tumor neovascularization and prognosis in human colorectal carcinoma patients. Clin Cancer Res 2000, 6:4064-4068.

31. Tu LX, Fang WY, Liu Z, Li X, He Y, Xie SM, Yao KT: [Establishment of a stable nasopharyngeal carcinoma cell line with lentivirus-mediated RNA interference for EIF4G1 gene silencing]. Nan Fang Yi Ke Da Xue Xue Bao 2009, 29:844-847. 851 .

doi: $10.1186 / 1476-4598-9-78$

Cite this article as: Tu et al., Over-expression of eukaryotic translation initiation factor 4 gamma 1 correlates with tumor progression and poor prognosis in nasopharyngeal carcinoma Molecular Cancer 2010, 9:78

\section{Submit your next manuscript to BioMed Central and take full advantage of:}

- Convenient online submission

- Thorough peer review

- No space constraints or color figure charges

- Immediate publication on acceptance

- Inclusion in PubMed, CAS, Scopus and Google Scholar

- Research which is freely available for redistribution

Submit your manuscript at www.biomedcentral.com/submit
C) Biomed Central 